\title{
The Virtual Museums of Caen: A case study on modes of representation of digital historical content.
}

\author{
John McCaffery*, Alan Miller*, Anna Vermehren ${ }^{\dagger}$ Adeola Fabola* \\ ${ }^{*}$ School of Computer Science, University of St Andrews, United Kingdom \\ jm726, ahr1, aef6@st-andrews.ac.uk \\ ${ }^{\dagger}$ Timespan, Helmsdale Heritage and Arts Center \\ director@timespan.org.uk
}

\begin{abstract}
In the early 19th Century much of the Strath of Kildonan was cleared of its people who were replaced by sheep farming. This pattern was repeated across the Scottish Highlands. In 2013 Timespan, Helmsdale Heritage and Arts Centre, hosted a program of activities to mark the 200th anniversary of the Clearances. The centrepiece of these activities was a community excavation of the Caen township in the Strath of Kildonan. Based upon the evidence of that excavation a digital model of the township was created using the Virtual Time Travel Platform. The Virtual World of Caen can be explored as part of an installation in Timespans storytelling room. Visitors can experience what life would have been like in the Strath of Kildonan in 1813. This paper reports how the model has been deployed in different settings and on various digital platforms. These include showcasing the model at the Helmsdale Highland Games where visitors could explore the township of the past on stereo head mounted displays, or a Virtual Museum website that welcomes visitors from around the globe, as well as using Google Cardboard to allow visitors to explore Caen today, the virtual reconstruction of Caen simultaneously whilst on the site.
\end{abstract}

Index Terms-Virtual Histories, 3D Web, interaction, learning.

\section{INTRODUCTION}

If we take ICOM's definition of a museum as: a museum is a non-profit, permanent institution in the service of society and its development, open to the public, which acquires, conserves, researches, communicates and exhibits the tangible and intangible heritage of humanity and its environment for the purposes of education, study and enjoyment; we can then define a virtual museum as: a digital entity that draws on the characteristics of a museum, in order to complement, enhance, or augment the museum experience through personalisation, interactivity and richness of content [1].

From the virtual museum distributed by Apple computer on CD ROM in 1992 [2] to the array of virtual museums documented in the V Must project [3] there are many different types and forms of Virtual Museum. Recent and ongoing advances in technology are opening up exciting opportunities. Commodity computer hardware can be used to create high fidelity immersive spaces, stereoscopic headsets can place the visitor in the middle of historic scenes, whilst mobile phones enable location based interpretation to create museums without walls. This paper discusses our experience in developing and using several virtual museums to represent a common subject. This has lead us to learn about the value, limitations and challenges associated with each type and to question the concept of Virtual Museum. We prefer conceptualising virtual

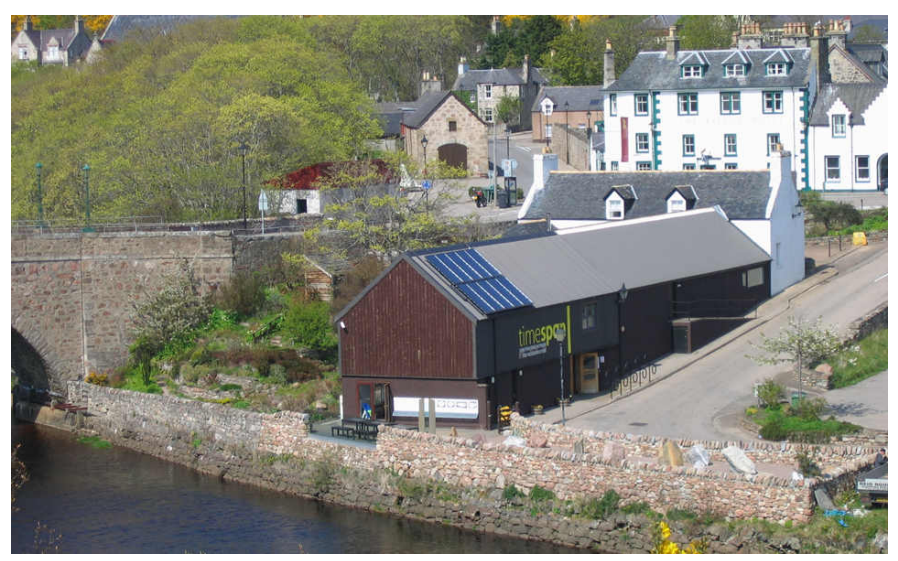

Fig. 1: The Timespan Museum and Arts Centre, Helmsdale

and digital representation within a single museum context where the virtual and physical are within a unified framework.

Timespan (Fig 1) is situated in the far north of Scotland in Helmsdale, Sutherland. Coined as a meeting place between the past, the present and the future, their work focuses on relationships with people and long-term creative development; they believe in new ideas and creative exchange, in access to excellence, technology and innovation, in promoting education and facilitating vibrant community dialogue. They aim to challenge perceptions of what can be delivered by a cultural organisation rooted in the distinctive, but fragile, socio-economic ecology of a large, rural and remote area.

The Caen township, located in the North East of Scotland in the Strath of Kildonan, two miles north-west of Helmsdale, provided shelter for people living off the land for some two thousand years. Life here came to an abrupt end at the start of the $19^{\text {th }}$ Century, when the inhabitants were cleared off the land to make way for sheep farming. On the $200^{\text {th }}$ anniversary of the Kildonan Clearances Timespan held a program of commemorative activities, artists residencies and research workshops all culminating in the two week long Translocation Festival in August 2013. Timespan also undertook a community excavation of a longhouse situated in the Caen township, and engaged St Andrews University to build a digital reconstruction based on the finds of the excavation. Based on Ordnance Survey data, a geo-physical survey and the finds of an excavation, a digital reconstruction was modelled to display the township of Caen and its surrounding landscape, depicting life in 1813. Since creating Virtual Caen [4], [5] we have explored immersive and mobile interaction with the virtual and real Caen. 

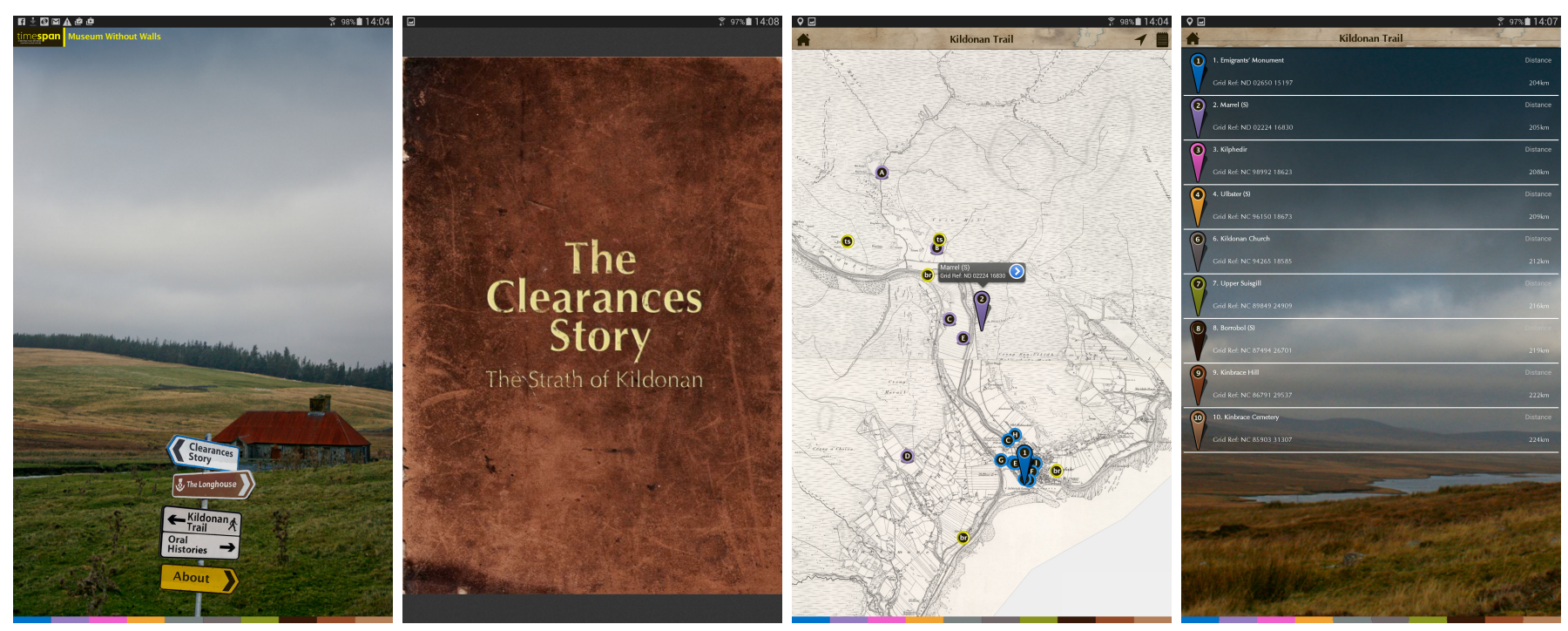

Fig. 2: Screenshots from the Timespan Museum without walls Clearances Trail Mobile Application

\section{The Virtual Museums}

Advances in 3D technology and the spread of digital literacies associated with computer gaming and mobile phones, open up the past making the exploration of heritage an engaging and exciting experience. Smart mobile phones are becoming ubiquitous [6]. The graphical capabilities of the next generation of mobile phones will be better than the current generation of console game platforms. Harnessing the power of technology in peoples pockets has the potential to enable mobile and immersive virtual reality to become part of the mainstream. Pairing photospheres and videospheres with low cost headsets like Google Cardboard offers the possibility of placing users in the middle of high fidelity digital scenes, enabling them to travel through space and time with the press of a button. Interacting with the township through virtual reality brings history alive to digital visitors both locally and across the globe. The five virtual museum types that we discuss are:

1) Museum without Walls: a location aware mobile app contextualises buildings and landscapes

2) Immersive Installation: synchronising multiple projection creates immersive virtual spaces

3) Web Virtual Museum: integrating multiple media and emergent digital representations with global reach

4) Portable Immersive Exhibition: featuring Stereoscopic Headsets and virtual 3D environments

5) On Site Immersive Exhibition: pairing mobile phones with Google Cardboard to enhance exploration

Out with the walls of Timespan the Kildonan Clearances Trail App acts as a tour guide through the Strath of Kildonan and offers insights into much of its historic landscape. Virtual Caen forms the heart of an immersive installation. The Web representation uses photospheres, video and audio to provide a taste of Caen, whilst a travelling exhibition using Oculus Rift technology offering a personalised, immersive experience. A Google Cardboard app brings photospheres of Caens past to the site today and contains onsite or remote exploration.

\section{A. Highland clearances Trail App}

The Highland Clearances app enables mobile exploration [7] and connects Timespan to the Strath of Kildonan. Under the banner of Museum Without Walls a Clearance Trail App was created to give visitors a downloadable guide to explore and understand the history of the Strath of Kildonan, a valley that spans from the mouth of the river Helmsdale to Kinbrace, 15 miles northwest of Helmsdale.

The app contains a wealth of audio and visual information about pre-historic settlements such as cairns, brochs and roundhouses to the many townships that populated the Strath till the early 19th century. It includes historical maps, imagery, text and audio, all embedded in the app for off line use (see Fig 2). The Kildonan Trail takes you on a journey to ten locations along the Strath of Kildonan to learn about the changes in the landscape over time, especially since the Clearances. Users can access audio narratives and browse through galleries of images from the past and present. All the sites are shown on GPS enabled trail maps. Other features include the Clearances Story of the Macpherson family as they face eviction from their home and emigration to North America, a depiction of a longhouse, an oral histories section with poems and songs, as well as a QR code kist game for youngsters. The trail app can be downloaded from Google Play and ITunes.

While the app uses the traditional mode of a tour guide, it enables the user to explore and learn at their own pace. Whilst the app can be used remotely it is designed to enhance a visitor experience to a real location. It provides interpretation through established media, but enables the user to choose interpretation relevant to their location either physical or imagined. It can provide interpretation over several square miles and successfully relies upon the users existing digital literacy to function. Since its launch in August 2012 the app has been downloaded more than 1000 times by people visiting the trail, and by people from the diaspora who want to access the information to aid their genealogy research. 

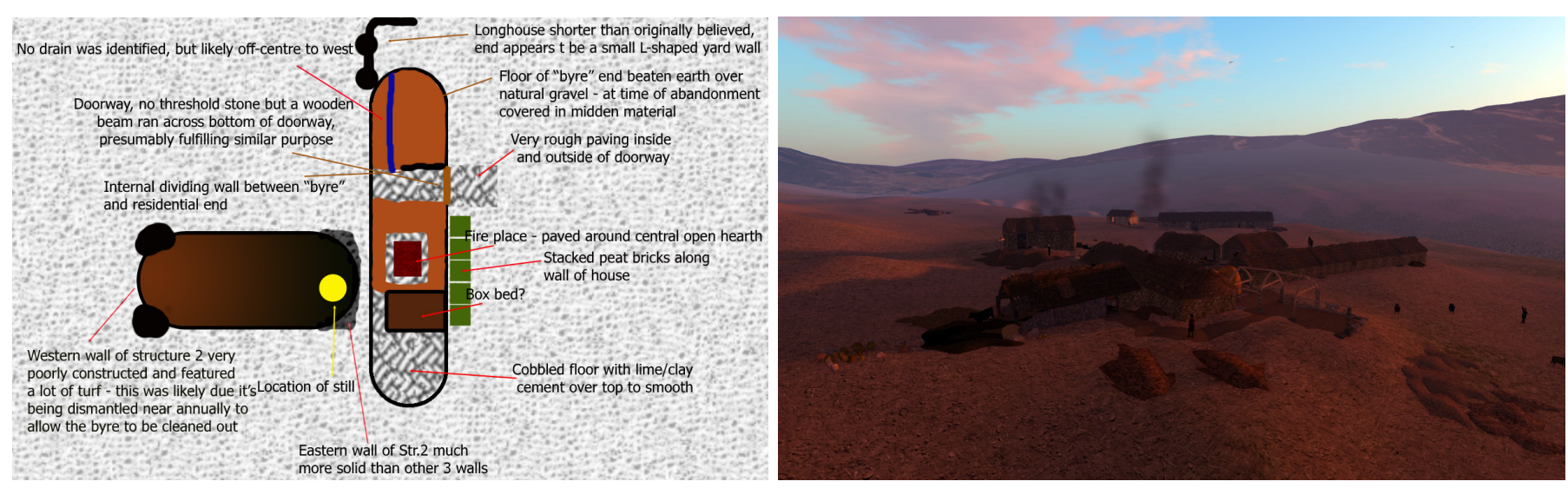

Fig. 3: Schematic of community excavation scope and finds and View of the Virtual Caen Township

\section{B. The Immersive Museum Installation}

At Timespan the story of the Kildonan Clearances is told through adjacent physical and virtual installations. The physical exhibition is made up of pre-existing collections, interpretation panels with info-graphic displays and artefacts discovered during the excavation. Next door in the storytelling room these artefacts are placed within the context of a digital reconstruction (Fig 3). The reconstruction is based upon archaeological [8], [9] and survey evidence [10] (see Fig 4). Built with open source software and commodity hardware the Virtual Caen Township forms an interactive installation [11]. It is a story of museums in the digital age [12]. Through the proxy of an avatar descendants of Caen could once more explore its landscapes and buildings [13]. Different modes of exploration await the visitor, from a fly through guided tour narrated by a local voice, to the opportunity to explore the landscape and township through the proxy of an avatar.

The system is made up of 3 screens, arranged as half a hexagon and lit by 3 full HD projectors. Each screen is nearly $2 \mathrm{~m}$ high. The central screen is wide screen proportions (16:9) whereas the side screens are traditional TV format (4:3). Altogether the three screens take up $150^{\circ}$ of the visitor's field of view. Under the central screen is a Microsoft Kinect. The system is powered by a small format computer installed in a concealed alcove to the left of the screens. The exhibit has an idle state, an automated sequence and a main menu. Menu selections are made by the visitor moving either hand left, right, up and down in front of the body (see Fig 5). Throughout the exhibit the gesture of raising one arm above the head maps to returning to the main menu. When the visitor selects a video they are taken to a confirmation prompt.

The exhibit features two separate in world configurations. In one the visitor moves the camera freely in three dimensions. There is no avatar, the camera can fly and is free to go through walls. In the other the visitor walks an avatar through the scene. The free camera movement allows for aerial views and a good sense of the geography, but lacks precision. Controlling the avatar is more effective for exploring inside the buildings and exploring the township itself. In the Caen exhibit the Guided Tour and Idle states are live fly-throughs. In the idle state the camera loops up and over the township, looking down from a height before swooping in through the largest longhouse.

\section{Virtual Museum Website}

The user is welcomed to the site by a video across the top of the page which provides a pacey fly over the Caen township (Fig 6). It correctly locates the township on a gentle south facing slope surrounded by hills, with a view of the sea in the distance. The visitor is invited to click on the video banner and enter an introductory version of virtual Caen. This web version is a series of linked photospheres. The number of spheres used was constrained by the need to load quickly whilst providing both a good overview and access to salient features.

There are three photospheres: the inside of the longhouse, the barn and the footpath. The longhouse setting shows a narrow, dark interior. Nearly two thirds of the building was once inhabited by people and the remaining third accommodated a byre for cattle. This particular longhouse was excavated, and many of the objects in the model were found during the dig. From here the user can see the rooms inside the house, and can navigate to the other two photospheres using mouse, arrows or touch.

A longhouse and barn were both excavated, in June 2013. Exciting discoveries included several pieces of copper from an illicit whisky still which are on display in Timespan. It is assumed that there were several stills dotted along the Caen burn. Although whisky may have not been produced in this barn, the depiction shows what an early $19^{\text {th }}$ century still would have looked like. From the footpath you can see the layout of Caen with its buildings, people and animals. The settlement may date from medieval times and was inhabited by local clans, including the Polsons, Sutherlands, Mathesons and Gordons. Each photosphere is set on auto rotate, which gives a 360 degree view of each of the scenes. Each scene has manual controls. The user can rotate the view, zoom in and out, retrieve contextual information and move to the next scene and toggle in and out of fullsscreen mode.

Below this interactive banner is a textual introduction to the site, followed by guidance on how to access a representation of the virtual world through a UNITY 3D plugin and through logging on to the Apollo virtual world server. There is also background information about the project, the research and activities that have gone into the creation of the model. In addition there are a number of other multimedia resources. 

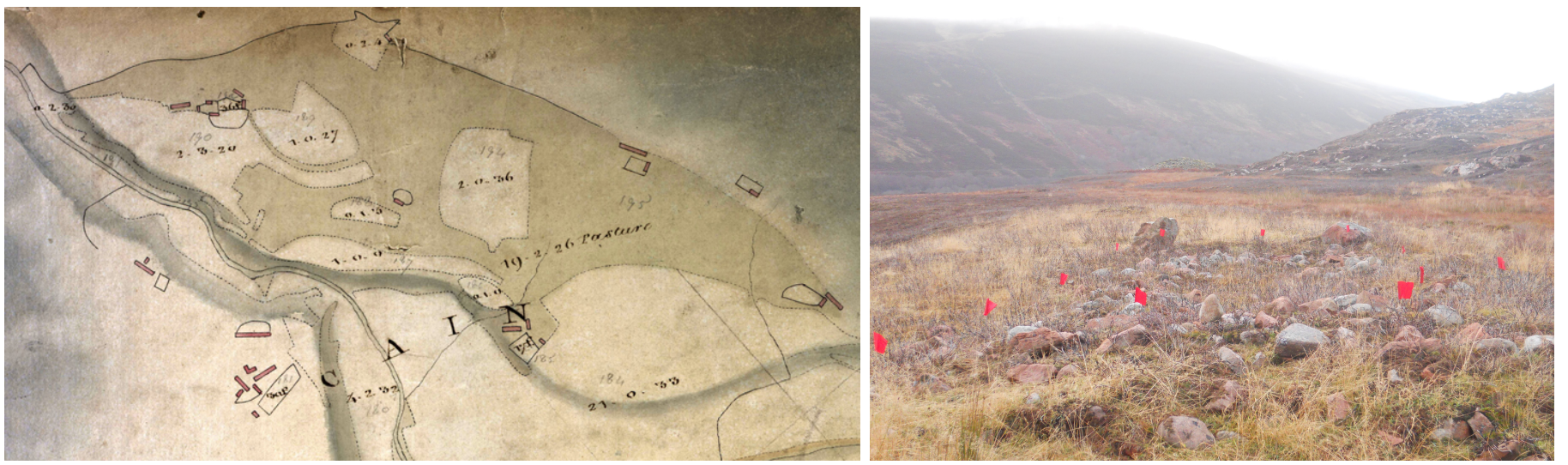

Fig. 4: Map of the Strath of Kildonan and Surveying the Caen Highland Township Site

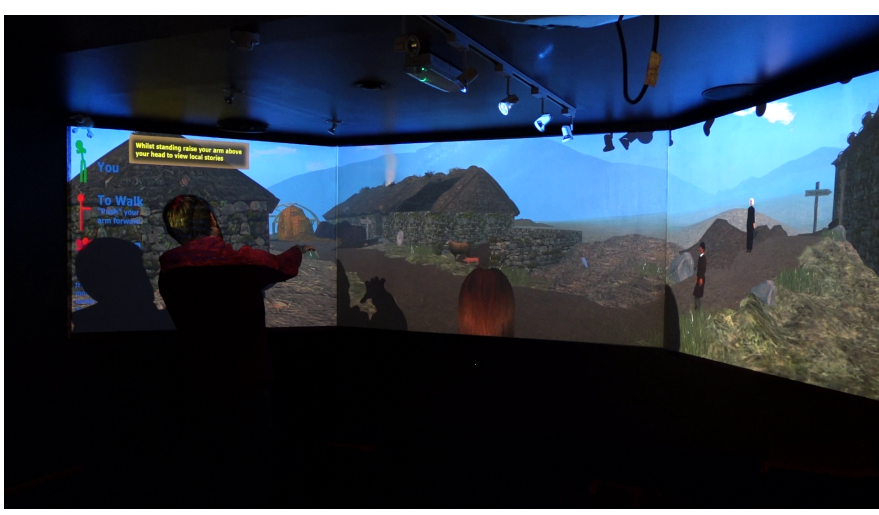

Fig. 5: Descendants of the Caen Township explore Virtual Caen

For example, a short video tour through the digital reconstruction gives insights into what life would have been like on the Strath of Kildonan at the start of the $19^{\text {th }}$ Century. This is the same narration that can be accessed in Timespan's storytelling room. There is also a ve minute video, which describes the process of creating the Virtual Caen township from the perspectives of the Timespan museum staff; and a series of stories and myths presented as audio recordings and in local voice, written by local school students.

The Virtual Museum website is hosted as a micro-site to Timespans website enables remote access to digital resources and to gain a first glance of Caen's digital reconstruction. The aim is to excite people about Timespan's innovative offer. The Virtual Museum website combines HTML5, CSS, Web GL and UNITY 3D to provide multiple views of virtual Caen. The visitor is swept through the landscape with a fly through video, linked photo-spheres enable high fidelity immersion from pre set viewpoints, a UNITY 3D plug provides freeform exploration of a township scene from and audio recordings relay local school students interpretations of local stories.

\section{Mobile Exhibition with Stereoscopic Headsets}

Panoramas where the viewer is placed in the centre of a scene were popular in Victorian Britain [14]. Often these were representations of the present. The visitor or group of visitors was placed in the centre of the panorama, which could be enhanced through mechanical movement, actors, smells and artificial wind. The great exhibitions of the age provided a fitting venue for these installations. However, they were large expensive and cumbersome affairs. It was not easy to change the scenes and repeat visits to the same scene were not particularly attractive. These theatrical depictions of an alternative reality were soon replaced by film as the popular mode of entertainment. Film offered the engagement of moving pictures, the ease of projection and the frequently changing content that could be offered. Yet, in a sense, the movies were a step back and away. The visitor was no longer in the middle of the scene but removed from it watching from afar with a crowd of people around.

Todays digital 3D representations in the cinema or games give the impression of depth when looking at a screen. These are constrained by being represented on a 2D surface. Consequently, whilst an illusion of 3D may be sustained when directly viewing the screen, the viewers conscious and subconscious are both aware that this is a representation and a distance is maintained from that representation. Additionally when one looks to the side or behind any illusion of being within the scene is broken. The digital domain allows return to the immersive, 3D, popular panorama views, on a personalised, changeable platform. Digital spheres, photo and video offer moving pictures, the possibility of creating and loading from libraries. They offer a synthesis of the best of $19^{\text {th }}$ Century panoramas and $21^{\text {st }}$ century film. Putting the visitor in the middle of a shared interactive experience lends itself to popularising the exploration of heritage.

The portable exhibition pairs Oculus Rift with a Local Area Network of portable computers. This has enables the Virtual World of Caen to be taken to schools, community centres and libraries. It enables the museum to reach out beyond its walls and provide a highly immersive engaging historic experience. By connecting an Oculus to the Virtual World of Caen visitors are placed in the centre of a world of the past. They can move their avatar using an X-box controller and see directly through the eyes of their avatar. The experience is a personal one compared to the cinema or the storytelling 


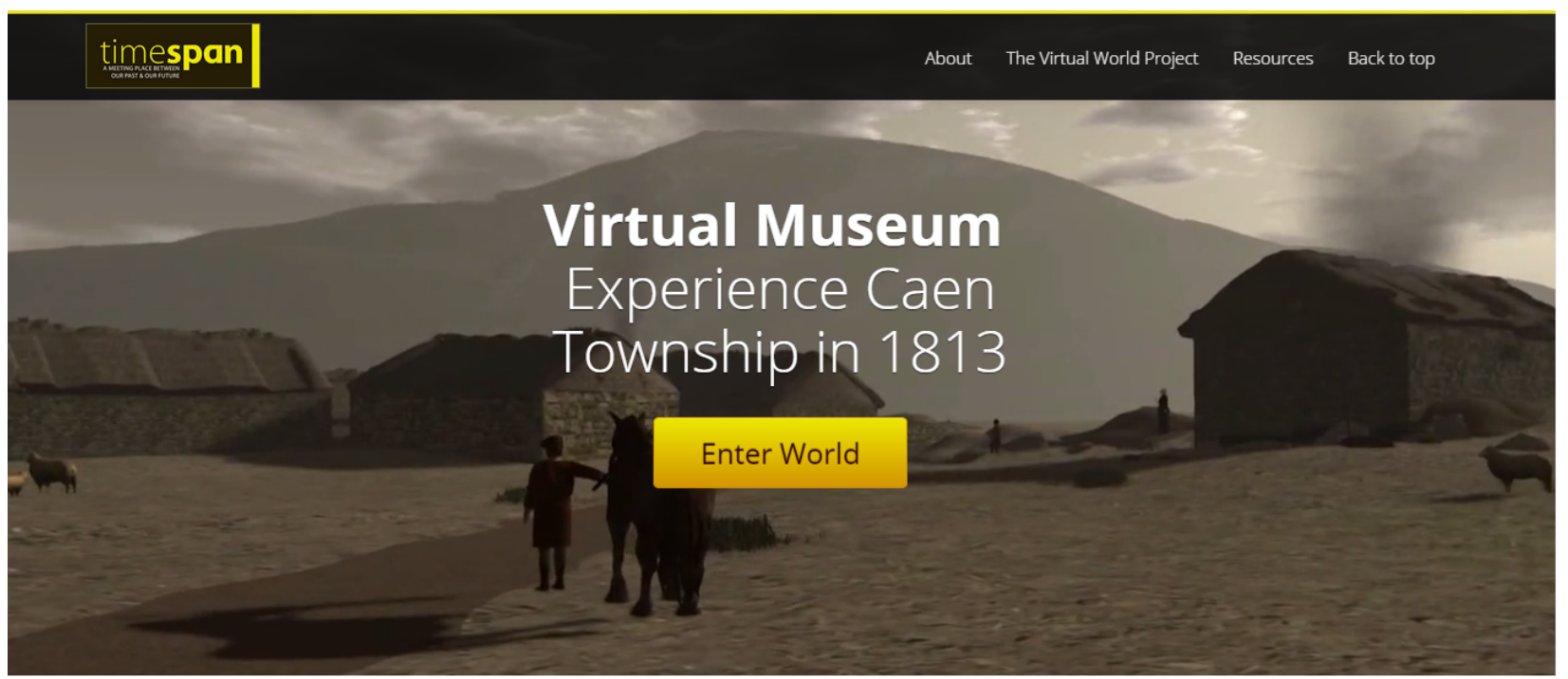

Fig. 6: A Screen shot of a scene from the Virtual Museums introductory video. When a player clicks on Enter World they are taken to a network of panoramas.

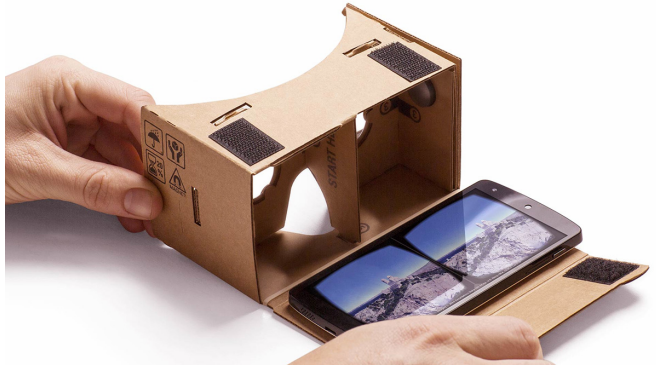

Fig. 8: Google Cardboard with phone inserted

room. Although there may be multiple avatars attached, each has their own personal view. In August 2014 we took the Virtual World of Caen to the Helmsdale Highland Games. Young and old explored the reconstruction, often getting their first experience of using a stereoscopic headset and travelling through time, digitally. Many found the experience engaging and invigorating, some found it disorientating; but all took something positive away from their first encounter with this technology.

\section{E. Mobile Exploration}

Mobile phones contain high definition screens for example the iPhone 5, HTC One and Samsung Note 5 all have screens with a higher resolution than the Oculus Rifts total resolution. They come ready equipped with GPS receiver, accelerometer and compass, which enable position, orientation and movement of the device to be discovered by applications.

Google cardboard (shown in Fig 8) enables mobile phones to be transformed into stereoscopic headsets which have the capability of taking a visitor into the middle of a historic scene. Google Cardboard offers a cheap casing into which a smart phone is inserted. The casing provides two lenses, so that the combined cardboard and phone can be used like a pair of binoculars. Intended primarily for games and watching
3D movies, Google Cardboard offers intriguing possibilities for developing heritage apps which give the visitor a truly immersive experience, placing them in the middle of a historic site. HTML5 combined with Web GL and wrapped up in a rapid application development environment make it relatively easy to make web pages that will work well with Google Cardboard and to combine those pages to create an App.

Using app technology enables content to work in locations that have no mobile signal, which is still a surprisingly large part of the globe. Due to no connectivity in the Strath of Kildonan the Clearance Trail App contains all the data required, and needs to be downloaded in full before venturing into the landscape. We have designed a mobile app for Caen, which acts as a 3D immersive guided tour to the past. The Google Cardboard App takes panoramas of the Caen township reconstruction and makes them accessible via mobile phone whilst on the site. It can be used in automatic, manual and location modes.

The app contains the following resources: an audio commentary, a series of stereoscopic video sequences which link together viewpoints, 3D stereoscopic panoramas, and 360 degree video of selected viewpoints. The guided tour starts at the Caen Burn, a panorama provides context for the location and the opportunity to hear an introduction. A short piece of video takes the visitor up stream and into the middle of the village, further panoramas show the longhouses inside and out, peat cutting, the corn kiln, kale yard, the site of the whiskey still and other sites. When visiting the physical site, the app finds the users location and presents the appropriate commentary and visuals for the location. When used remotely there is a choice between timed and manual modes. In timed mode the app moves through the trail automatically; in manual mode the user positions a central site over an arrow to move to the next point on the trail. A prototype of the app was trialled at the True North conference hosted by Timespan, where it received positive reviews. Technology like this adds significant value to the creation of historical interpretation, as it enhances the on-site experience at the historic location. 


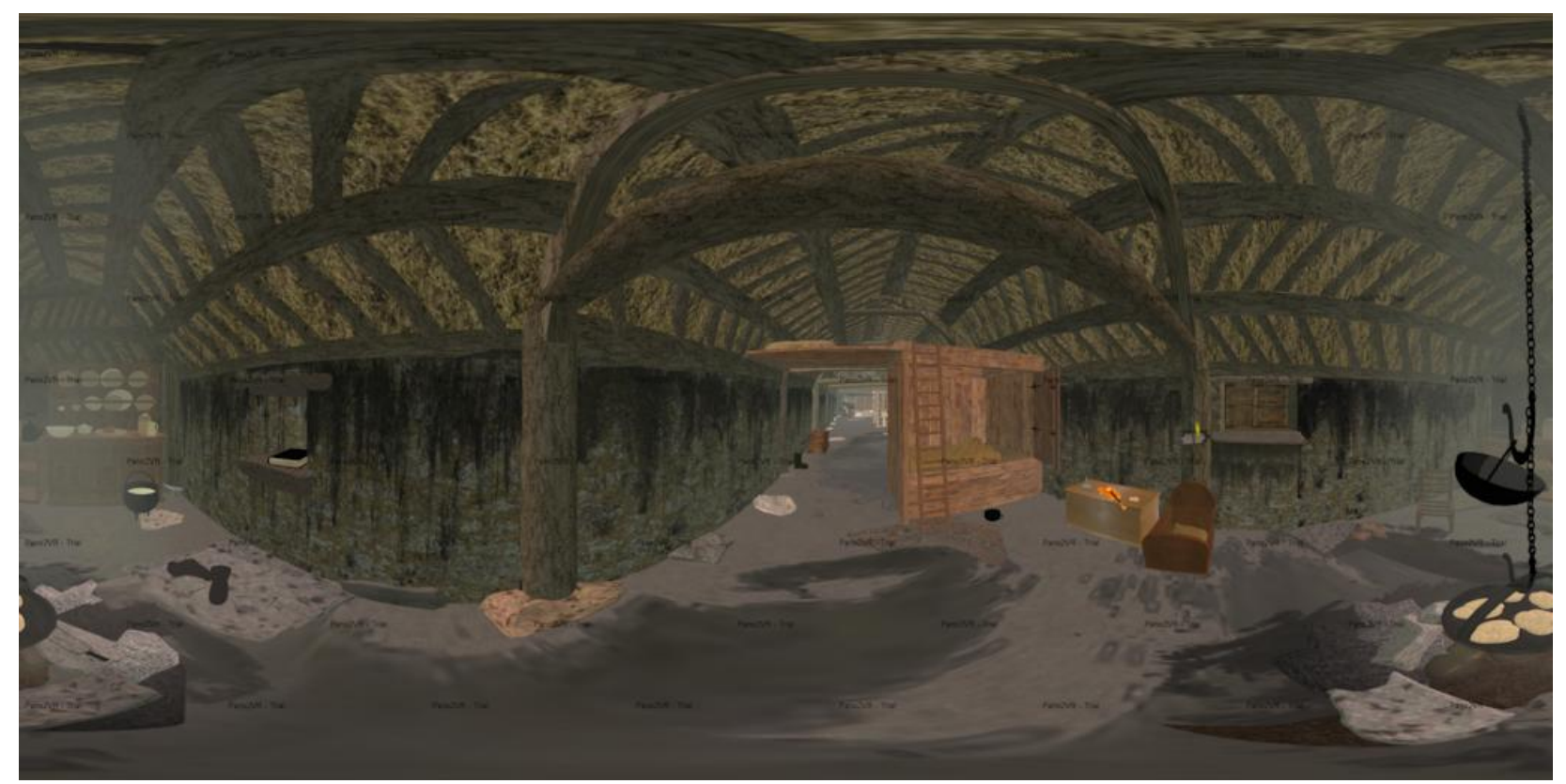

Fig. 7: Equirectangular projection of the inside of a longhouse. This is a representation of a sphere and maps longitude directly to the horizontal coordinate, and latitude to the vertical coordinate. This projection is used for the source images in the panoramas

\section{EVALUATION OF IMMERSIVE INSTALLATION}

In this section we discuss an evaluation of the Caen Virtual Museums. We report on a user study of the Caen Virtual World installation which addresses usability and value along with evaluation from stakeholders. The full breakdown of results and discussion of methodology is given in [15]. We then illustrate the changing relationship between system limitations and functionality by discussing the Museum Installation and Web Virtual Museum.

Usability is challenging as visitors need to be able to walk up and use the exhibit without training.The SUS metric provides a generic and established mechanism for measuring the usability of systems. In spite of the use of technology that might be unfamiliar to many of the visitors the SUS scores are above average. Each statement is scored between 1 and 5 where five indicates strong agreement. Against the frequency distribution of all SUS evaluated systems this puts the exhibit around the $70^{\text {th }}$ percentile. The most positive responses indicate that users do not find it cumbersome and are confident using it. There is a learning curve, but it is easy to scale. Users were less positive that it is easy to use, however even here the mean result is more positive than neutral.

1) I would imagine that most people would learn to use this system very quickly 4.3 .

2) I felt very confident using the system 4.4.

3) I thought the system was easy to use 3.8 .

4) I would enjoy exploring other areas of history using a similar system 4.5 .

5) The big screen(s) made it seem more real 4.7.

We conclude that the interactive virtual world was appropriate as a walk up and use interactive installation, without the need for staff presence at the exhibit. However, a proportion of users did not want to engage with the interactive experience. They were catered for through the provision of a fly through and guided tour, which was triggered through the Kinect detecting their presence.

In evaluating value Ten Likert statements were presented to visitors. These statements are designed to go beyond general usability and ease of use to give a more complete picture of how visitors are experiencing the exhibit. They measure engagement, immersion, learning, enjoyment and how effectively users are interacting with the content of the exhibits. Four of the questions are given below.

1) The exhibit helped me imagine what it would have been like to live in Caen. 4.6

2) I would now like to find out more about life in Caen. 4.6

3) I enjoyed using gestures to control exploration. 4.0

4) Walking about the reconstruction helped me think about how people used to live. 4.3

5) I found the exhibit difficult to understand. 1.3

These results suggest that users found the Virtual World of Caen stimulated their imagination, helped people understand what it was like to live in the past. The project has also been beneficial for building a strong track record in the innovative digital development of the museum, and in gaining the interest of funding bodies such as Creative Scotland, Museums Galleries Scotland and the Heritage Lottery Fund. Press coverage received by national and local papers, national radio and TV has strengthened the museum's medium term goal to become a sector leader in the Northern Highlands. Jean Sargent commented:

As Chair of Timespan, I am particularly delighted to see this collaboration with St Andrews University. We find that working with academics makes our projects more exciting and adds depth to our research. It is easy to become entrenched in your own little world so we find that these collaborations bring fresh ideas and knowledge to Helmsdale. 

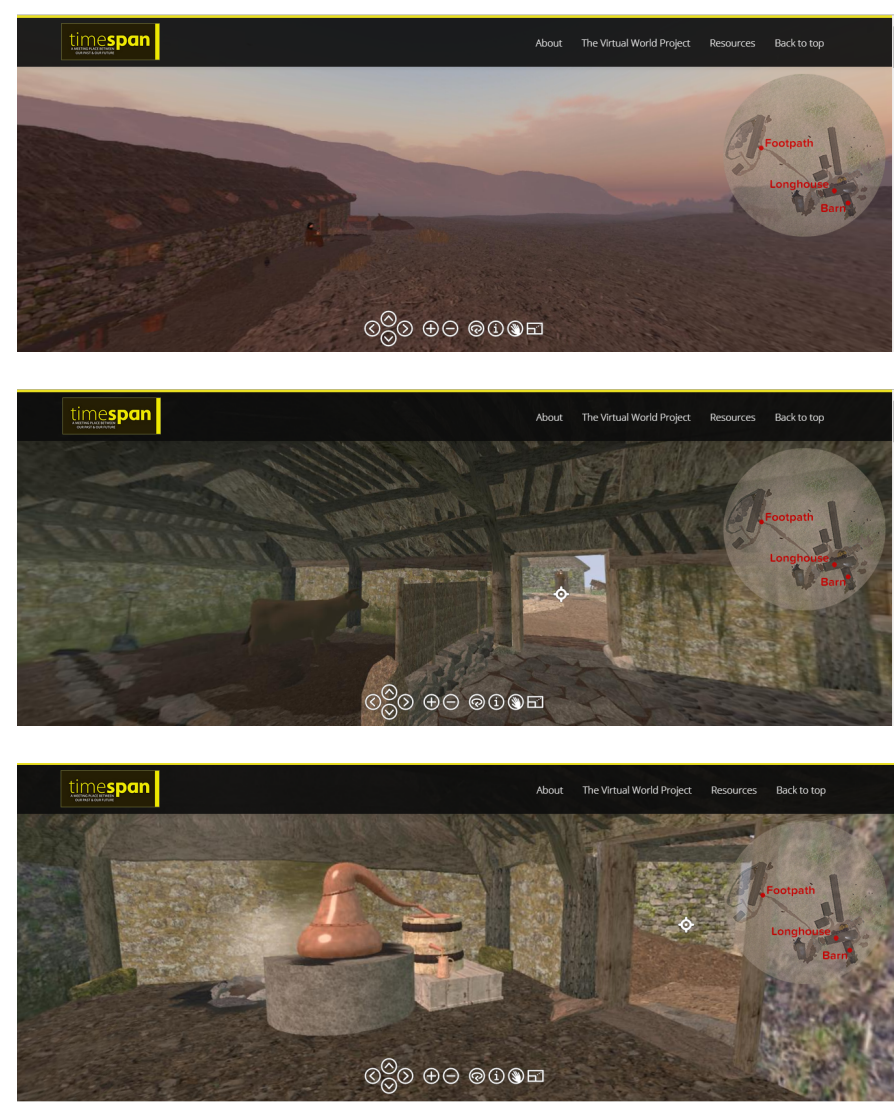

Fig. 9: Panoramas are embedded in a Web Page: each panorama gives a 360degree full screen view of the Scene and contains a map of the network of panoramas. User controls enable navigation. There are panoramas from the footpath, the longhouse and the reconstruction of a whisky Still found in excavation

With the deployment of HTML5 and WebGL providing access to hardware acceleration features we have the tools to embed 3D scenes in web pages to create more immersive experiences that can be accessed globally. However, it was not possible to fully replicate the immersive installation in a web context. The 3D browser based performance does not match up to that of a standalone client. The complexity of model supported, the scale of the landscape that can be explored and the response speed all constrain the experience. The Web Virtual Museum will be accessed over variable network conditions [16], [17] by computers with a wide range of capabilities. Consequently, the freeform exploration of 3D the full Virtual Caen embedded in the web page was confined to a single longhouse [18], [19]. Video, photospheres and audio provide a taste of the wider scope of the virtual Caen installation, which serves to encourage visitors to the museum.

Each of the Virtual Museums have a relationship to the physical; that of museum exhibitions, walking around remnants of historic sites, or showcasing models to a mixed audience at festivals, conferences and events. The digital content draws upon the same physical reality and the same digital resources. These are compared in Table I.

\section{CONClusion AND Future Work}

Future work addresses two challenges; integrating emergent technologies with existing museum exhibition creation and management, and developing digital asset management systems which provide multiple views onto the same digital assets.

We propose a system which enables these digital resources to become common goods and to be integrated into museum interpretation and archival systems. This will enable connections between the real and the digital to be established and leveraged in digital interpretation. At the same time the digital assets need to be managed so that the same asset may be used in multiple contexts. The mobile app, installation and Oculus systems are all providing views onto the same digital reconstruction. But that reconstruction needs to be rendered in different ways depending on context, computational resource and graphical capabilities. The Web based Virtual Museum, has the ability to present in multiple ways, video, panorama and 3D scenes, but is not able to handle the scale and detail of a museum installation. The Oculus Rift can support freeform exploration and immersion. Google Cardboard is a strong platform for mobile on-site explorations. Here it makes sense to sacrifice freedom of movement for an on location high fidelity experience.

These design choices are based upon experience of using the technologies in the field, of evaluation of systems and appreciation of user priorities, developed through measurement and observation in the field. We expect these modes of interaction to become part of the common interpretation in museums and heritage sites [20].

In conclusion this paper has documented different ways in which the Caen digital model has been used to complement, enhance or augment Timespans modes of heritage interpretation. It is about a single story, the Kildonan Clearances, told in a multitude of ways. It recounts multiple modes of digital presentation, which enable the story to be told using different modes of interaction appropriate for different use cases. Digital assets and volunteer research conducted to create a Museum without Walls App fed into the creation of the Virtual World of Caen model, which turned Timespans storytelling room into an immersive digital experience. Assets from the virtual model were then migrated into a web based virtual museum, which enabled access from across the globe. A combination of media were required to communicate all aspects of the original model. Stereoscopic headsets in the form of Oculus Rift offered a 360 degree individual immersive experience. A travelling LAN (Local Area Network) enabled exploratory workshops with several users interacting online in community centres and schools. A google cardboard app harnesses the graphics capabilities of mobile phones to take visitors into the middle of the scene. The Oculus offered a highly immersive experience with a wide field of view and free form exploration. Google Cardboard offers the ability to use cheaply available technology to explore Caens past with panoramas, 360 degree video and stereoscopic video creating an engaging educational experience packaged into an app and accessible on site. For each system it was necessary to identify the relationship between the users quality of service and the quality of service the client hardware and software were able to support. We used several techniques to enable an appropriate level of performance to be achieved whilst allowing the virtual visitor to achieve an holistic appreciation of the reconstructed township. The test of success lies not just in the material 

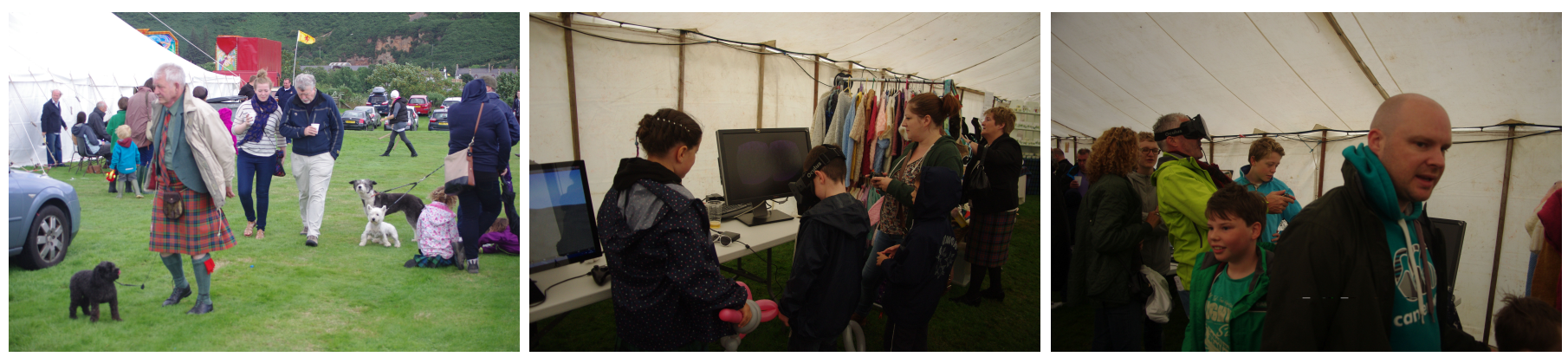

Fig. 10: Helmsdale Highland Games, Exploring the Virtual Caen Township, with Stereoscopic Head Mounted displays

\begin{tabular}{|c|c|c|c|c|}
\hline & Real World & Virtual World & Literacy & Primary Value and Use Context \\
\hline $\begin{array}{l}\text { Museum Without Walls } \\
\text { (Virtual Trails) }\end{array}$ & $\begin{array}{l}\text { Direct exploration } \\
\text { of a wide area }\end{array}$ & $\begin{array}{l}\text { Digital representation aims to en- } \\
\text { hance real world exploration }\end{array}$ & $\begin{array}{l}\text { Utilises } \\
\text { phone literacies }\end{array}$ & $\begin{array}{l}\text { Enhances exploration of physical locations } \\
\text { and connects museums to their hinterland }\end{array}$ \\
\hline Immersive Installation & $\begin{array}{l}\text { Interpretation and } \\
\text { artefacts co-located } \\
\text { with virtual exhibit }\end{array}$ & $\begin{array}{l}\text { Representation of a complete digi- } \\
\text { tal scene, including audio and char- } \\
\text { acters. The exhibition supports free } \\
\text { form exploration and is interactive }\end{array}$ & $\begin{array}{lr}\text { Utilises } & \text { computer } \\
\text { game } & \text { digital } \\
\text { literacies } & \end{array}$ & $\begin{array}{l}\text { Enables immersive and interactive free form } \\
\text { exploration of the past, that provides a new } \\
\text { dimension to museum exhibits and enhances } \\
\text { the visitor experience. It is useful to provide } \\
\text { automatic guided tours alongside interactive } \\
\text { features }\end{array}$ \\
\hline $\begin{array}{l}\text { Portable Immersive Exhibi- } \\
\text { tion }\end{array}$ & $\begin{array}{l}\text { Set up in school, } \\
\text { community } \\
\text { or library }\end{array}$ & $\begin{array}{l}\text { Provides high quality, highly im- } \\
\text { mersive free form exploration of } \\
\text { digital scenes }\end{array}$ & $\begin{array}{lr}\begin{array}{l}\text { Utilises } \\
\text { game } \\
\text { literacies }\end{array} & \text { computer } \\
\end{array}$ & $\begin{array}{l}\text { Provides a great wow factor and generates } \\
\text { lots of interest. Provides a great focus for } \\
\text { community outreach and co-creation projects }\end{array}$ \\
\hline $\begin{array}{l}\text { Onsite Immersive Installa- } \\
\text { tion }\end{array}$ & $\begin{array}{l}\text { Can be used on sites } \\
\text { of historical interest }\end{array}$ & $\begin{array}{l}\text { Provides cross reality experience } \\
\text { enabling comparison of real and } \\
\text { virtual co located spaces }\end{array}$ & $\begin{array}{l}\text { Can be used with or } \\
\text { without headset }\end{array}$ & $\begin{array}{l}\text { Utilising photosphere and videosphere tech- } \\
\text { nology, interactve, provides high fidelity rep- } \\
\text { resentations of the past, accesible on site or } \\
\text { remotely }\end{array}$ \\
\hline
\end{tabular}

TABLE I: Summary of experience with the Virtual Museums of Caen, relationship to real world, capabilities within the virtual, digital literacies and value.

created and presented but also in the level of participation [21].

\section{REFERENCES}

[1] S. Hazan, S. Hermon, R. Turra, G. Pedrazzi, M. Franchi, and M. Wallergard, "Theory design (virtual museum)," VMust, Tech. Rep., 2014. [Online]. Available: http://www.vmust.net/sites/default/files/D3.1_update.pdf

[2] G. Miller, E. Hoffert, S. E. Chen, E. PAtterson, D. Blackketter, and S. Rubim, "The virtual museum: Interactive $3 \mathrm{~d}$ navigation of a multimedia database," The Journal of Visualisation and Computer Animation, 1992.

[3] V. M. T. Network. $(2015,4)$ Vmust. [Online]. Available: https://www.vmust.net/

[4] J. P. McCaffery, A. H. D. Miller, S. E. Kennedy, A. Vermehren, C. Lefley, and K. Strickland, "Exploring heritage through time and space: supporting community reflection on the highland clearances," in Proceedings of UNESCO Congress on Digital Heritage. IEEE, 2013.

[5] T. Dawson, I. A. Oliver, A. H. D. Miller, A. Vermehren, and S. E. Kennedy, "Digitally enhanced community rescue archaeology," in Proceedings of UNESCO Congress on Digital Heritage. IEEE, 2013.

[6] L. T. . K. Walker, Digital Technologies and The Museum Experience. Handheld Guides and Other Media., L. T. . K. Walker, Ed. AltaMira Press, 2010.

[7] C. J. Davies, A. H. D. Miller, and C. Allison, "Mobile cross reality for cultural heritage," in Proceedings of UNESCO Congress on Digital HEritage. IEEE, 2013.

[8] K. M. Strikland, "Kildonan clearances bicentenary: The final days of a clearance settlement," History Scotland, vol. 19, pp. 14-17, 2014.

[9] _- "Translocation: Excavating the highland clearances," Archaeology Scotland, vol. 19, pp. 14-17, 2014.

[10] S. E. Kennedy, R. Fawcett, A. H. D. Miller, R. J. Sweetman, L. Dow, A. Campbell, I. A. Oliver, J. P. McCaffery, and C. Allison, "Exploring canons and cathedrals with open virtual worlds: The recreation of st andrews cathedral, st andrews day, 1318," in Proceedings of UNESCO Congress on Digital Heritage. IEEE, 2013.

[11] A. H. D. Miller, D. L, A. C., and K. S, "Exploring exhibitions in virtual worlds," in Re-thinking technology in museums, 2011.

[12] R. Parry, Museums in a Digital Age. Routeledge, 2010.

[13] K. Getchell, A. Miller, R. Nicoll, R. Sweetman, and C. Allison, "Games methodologies and immersive environments for virtual fieldwork," Learning Technologies, IEEE Transactions on, vol. 3, no. 4, pp. 281293, 2010.

[14] F. C. . S. Kenderdine, Theorizing Digital Cultural Heritage. A Critical Discourse, F. C. . S. Kenderdine, Ed. MIT Press, 2010.

[15] J. McCaffery, "The virtual time travel platform: Engineering a generic framework for immersive cultural heritage scenes," Ph.D. dissertation, School of Computer Science, University of St Andrews, 2015.

[16] I. A. Oliver, A. H. Miller, and C. Allison, "Virtual worlds, real traffic: Interaction and adaptation," in Proceedings of the First Annual ACM SIGMM Conference on Multimedia Systems, ser. MMSys '10. New York, NY, USA: ACM, 2010, pp. 305-316. [Online]. Available: http://doi.acm.org/10.1145/1730836.1730873

[17] I. Oliver, A. Miller, and C. Allison, "Mongoose: throughput redistributing virtual world," in Computer Communications and Networks (ICCCN), 2012 21st International Conference on. IEEE, July 2012, pp. $1-9$.

[18] M. Claypool, "The effect of latency on user performance in real-time strategy games," Computer Networks, vol. 49, no. 1, pp. 52-70, 2005.

[19] M. Claypool and K. Claypool, "Latency and player actions in online games," Commun. ACM, vol. 49, no. 11, pp. 40-45, 2006.

[20] R. R. Janes:, Museums in a Troubled World. Renewal, Irrelevance or Collapse? Routeledge, 2009.

[21] N. Simon, The Participatory Museum. Santa Cruz, CA: Museum 2.0., 2010. 